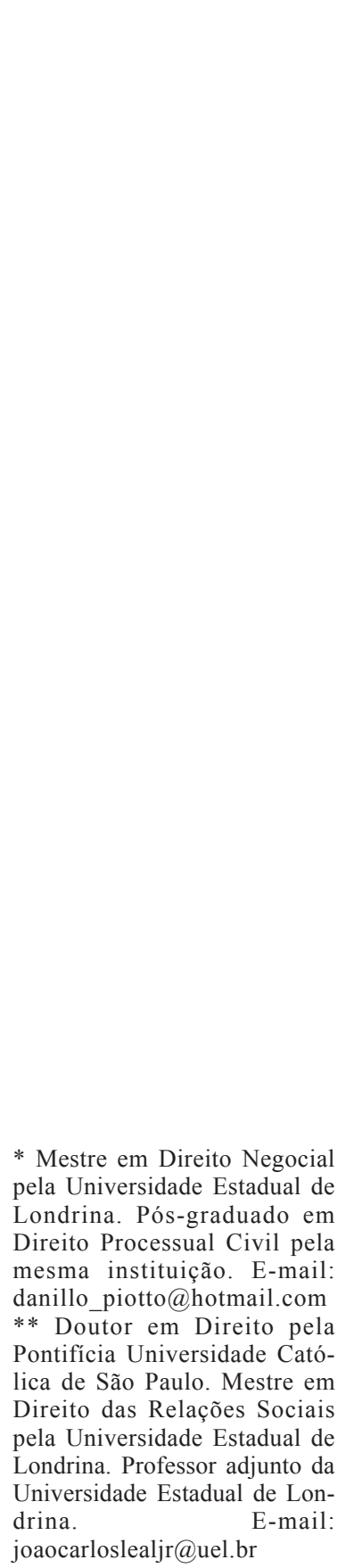

\section{A Natureza Jurídica do Título Executivo: da polêmica instalada entre Liebman e Carnelutti às teorias que se seguiram}

\author{
The Legal Status of Enforcement: THE \\ CONTROVERSY INSTALLED BETWEEN LIEBMAN AND \\ Carnelutti The THEORY THAT FOLlOWED
}

\author{
Danillo Chimera Piotto * \\ Francisco Emílio Baleotti **
}

Resumo: Trata da figura do título executivo, do contexto histórico que propiciou seu surgimento às teorias que tentam explicar sua natureza jurídica, passando pela célebre polêmica havida entre Carnelutti e Liebman e as releituras atuais da moderna ciência processual.

Palavras-chave: Título Executivo. Ato. Documento. Processo. Efetividade.

Abstract: This work aims with the enforceable title figure, its origin and historical context, and approaches the theories that intent to explain its juridical nature, through the famous controversy between Carnelutti and Liebman and the current conceptions in the modern juridical science.

Keywords: Enforceable title. Act. Document. Procedure. Effectiveness. 


\section{INTRODUÇÃO}

Partindo-se da inconteste assertiva de que o homem está fadado a viver em sociedade, isto é, conviver ${ }^{1}$, não menos axiomático se afigura sustentar que esta convivência necessita de regramento, sob pena de se instalar a desordem, contexto apto a obstar o progresso e o desenvolvimento social estes sustentáculos para o exercício pleno da dignidade da pessoa humana, garantia eleita como fundamental pelo modelo Constitucional Democrático vigente.

É que se mesmo por instinto de sobrevivência está o homem destinado a habitar em coletividade, não há como deixar de reconhecer em sua natureza o aflorar constante de 'particulares entendimentos sobre a realidade' que o cerca. E, justamente em decorrência desta percepção de mundo ser particular, por vezes, podem ocorrer conflitos entre os seres componentes desta sociedade, os quais, como adrede aludido, necessitam regramento e solução, sob pena de acarretarem acentuada instabilidade social.

Um breve olhar histórico faz denotar, porém, que o simples estabelecimento de regras de conduta, facultada, dessarte, sua adoção pelos indivíduos do grupo social, torna-se insuficiente frente à pretensão de pacificação e organização da coletividade. De maneira que, quase naturalmente, foi-se diuturnamente construindo todo um arcabouço hábil a assegurar a observância por parte dos indivíduos àquelas regras sociais de conduta.

Como bem expõe Giacóia (2004, p.30) ficou claro que "o homem não se associa espontaneamente a uma ordem sem normas capazes de coerção"; ou ainda, como reverbera Theodoro Junior (2007, p.6), "o equilibrio e o desenvolvimento sociais só ocorreriam com regras de observância obrigatória”.

$\mathrm{Na}$ inexorável marcha da história, elegeu-se, por fim, o Estado como ente detentor da força para a imposição obrigatória destas normas de conduta. Distinguem-se, assim, os preceitos jurídicos das demais espécies normativas existentes no universo social: detém a norma jurídica coercibilidade; implica dizer, não observadas 'sponti propria' por seus destinatários, concedem elas mesmas ao Estado poder para fazê-las serem cumpridas independentemente da vontade dos indivíduos a que se dirigem. Impõe o Estado, destarte, sanção ${ }^{2}$ àquele que lesiona o ordenamento jurídico:

\footnotetext{
${ }^{1}$ Gomes (2008, p.6) observa que: "A vida humana concretiza-se por meio da convivência".

2 Sanção é, em geral, a medida estabelecida pelo direito como consequência do fato ilícito (LIEBMAN, 2003, p.178).
} 
As medidas que o próprio ordenamento jurídico traça para que o Estado possa invadir a esfera de autonomia do indivíduo e fazer cumprir efetivamente a regra do direito, vem a ser o que se denomina sanção da norma jurídica (THEODORO, 1999, p.32).

No contexto do direito processual, a realização pelo Estado, por intermédio de órgãos jurisdicionais, de atividades cujo desiderato é dar atuação à sanção prevista pela norma denomina-se execução ${ }^{3}$ (LIEBMAN apud THEODORO JUNIOR, 1999, p.32). Vê-se, pois, em apertada síntese, que por intermédio da execução, o Estado, no bojo de um processo, substitui o transgressor de determinada norma jurídica, realizando aquela conduta que deveria já ter sido por ele praticada.

$\mathrm{O}$ 'gatilho' autorizador do Estado à imiscuir-se na esfera privada do particular por intermédio da execução denomina-se título executivo, é quanto a natureza jurídica deste gatilho que se debruçará o presente estudo.

\section{PONTUAÇÕES DE ORDEM HISTÓRICA: A ACTIO IUDICATI ROMANA E O SURGIMENTO DOS TÍTULOS EXECUTIVOS EXTRAJUDICIAIS}

Leciona Theodoro Junior (1999, p.33) que o Direito Romano não conhecia outro título que não fosse a sentença judicial, isto porque para a sociedade romana se tinha por absolutamente inaceitável a execução, a invasão da esfera privatística do indivíduo, sem prévio conhecimento exauriente de suas razões.

É verdade, porém, que na estrutura primitiva romana, superada a fase cognitiva e imposta a condenação pelo árbitro, o procedimento executivo era severo posto que de natureza pessoal e privada: ao credor era dado o direito de agir fisicamente sobre a pessoa do devedor. Não obtido o pagamento do débito pelo próprio devedor ou por algum amigo seu, era intentada sua venda em mercado por três vezes, sendo, a partir daí, possibilitada sua redução à condição de escravo ou, fossem muitos os credores, seu esquartejamento (GRECO, 1999, p.11).

\footnotetext{
${ }^{3}$ Perfilha-se este estudo à corrente doutrinária que enxerga em toda atividade estatal destinada a satisfação prática da norma um exercício da força - de maneira que se afigura como pleonástica a utilização da expressão composta execução-forçada. O cumprimento voluntário de uma obrigação não é execução, a respeito cf. Theodoro Junior (1999, p.41). Em sentido contrário, Dinamarco (2009, p.34) que reconhece, na linha de Liebman, a existência de atos executivos impróprios.
} 
Mais a frente, e aqui já se começa a aproximar o Direito Romano do nosso contemporâneo, a partir de 326 a.C. com o advento da Lex Poetelia, os romanos passam a abandonar a execução pessoal e particular, desenvolvendo o conceito de execução real $^{4}$, num processo constante de evolução até a formulação da actio iudicati.

Nesta fase histórica a execução passa a ocorrer por intermédio do Estado e, desde então, sobreleva-se o processo de conhecimento sobre o executivo. Nas palavras de José Alberto dos Reis (apud GRECO, 1999, p.18) "a preocupação com a defesa do devedor prevalece sobre a proteção do direito do credor".

Questão que se revelou tormentosa é que a actio iudicati possibilitava ao devedor, já após firmada a condenação, um lapso temporal para o adimplemento espontâneo da obrigação, o tempus iudicti, ao cabo do qual, mantendo-se inerte o devedor, se impunha ao credor novamente recorrer ao juiz e provar o inadimplemento em novo processo cognitivo. Só então, demonstrado cabalmente que não houvera sponti propria a quitação do débito pelo devedor naquele lapso temporal, se abria ao credor a possibilidade de obter do Estado o que hoje se denomina tutela executiva.

É nesse contexto que a dominação germânica sobre a Europa acabou por representar retrocesso ao processo de conhecimento, isto porque os povos bárbaros adotavam a execução pessoal privada. Somente após certo decurso de tempo, explica Greco (1999, p.28), o fortalecimento da autoridade permitiu o retorno da execução às mãos do Estado, agora, porém, já não mais sendo necessária a actio iudicati, com seu moroso [duplo] procedimento em contraditório.

Nascia a executio parata, pela qual era dado ao juiz, aproveitandose dos atos cognitivos já praticados, dar início aos atos executórios por simples requerimento do credor:

Para obter essa nova prestação jurisdicional [a execução] bastava ao credor endereçar um requerimento ao juiz e este, sem ouvir a parte contrária, lançava mão das "faculdades e deveres inerentes ao seu ofício" e praticava os "atos necessários a assegurar a execução da sentença por ele proferida" (LIEBMAN apud THEODORO JUNIOR, 1999, p.34).

\footnotetext{
${ }^{4}$ Execução real: execução que recai sobre coisas; bens.
} 
A narrativa histórica ora desenvolvida revela uma interessante conjuntura daquela sociedade antiga: de um lado a trava imposta pelas raízes romanas à violência da execução germânica; de outro a complacência exacerbada do direito latino para com o devedor, o que em certa medida acabava por se revelar um empecilho ao desenvolvimento do comércio que começava a despontar nos burgos medievos. Oportuna nessa senda a análise de Medina (2002, p.99):

Trata-se de optar entre a certeza e a urgência, de eleger um dos valores como principal norteador da criação dos provimentos jurisdicionais executivos. Obviamente, confrontam-se, em relação a tal embate, os interesses do demandante e do demandado: o primeiro esperando atendimento à sua pretensão pelo modo mais rápido possível; o segundo, buscando, antes de (eventualmente) sucumbir àquela pretensão, cognição o mais intensa possível acerca do direito afirmado pelo credor, bem como sua defesa.

Foi então, a necessidade de progresso social - e sempre o é - mormente no que tange ao fortalecimento do comércio e da necessidade de se conceder velocidade à circulação do crédito, que ocasionou o surgimento dos denominados instrumenta guarentigiata ou confessionata.

Por intermédio deles possibilitou-se que determinados negócios particulares, sob rigorosas condições, facultassem ao credor suprimir a fase cognitiva de um processo, alcançando-se diretamente a execução, podendo-se constranger diretamente o patrimônio devedor, sem que houvesse a anterior imposição de demonstração da relação que havia gerado a obrigação.

A moderna concepção de título executivo representa solução de compromisso entre dois antigos sistemas jurídicos, fundados em valores antagônicos: o sistema romano, segundo o qual "mesmo depois de obtida uma sentença de condenação o credor não podia usar de meios executivos e tinha de propor nova ação", a actio iudicati, a fim de verificar se o seu direito ainda subsistia, e o germânico, segundo o qual o credor pode começar por um ato executivo, a penhora, e depois é que pode surgir, por iniciativa do devedor, uma espécie de juízo de apreciação e de conhecimento (ZAVASCKI, 1999, p.65).

Ao fim de largo desenvolvimento científico processual, a diferença entre ambas as espécies de execução de título - judicial e extrajudicial - explica Theodoro Junior (1999, p.35), restou no plano da amplitude das defesas que podiam ser opostas pelo devedor: à primeira um reduzidíssimo rol, haja vista o 
moroso prévio processo de formação da coisa julgada; à segunda, uma ampla gama de possibilidades, consubstanciando-se em verdadeira ação cognitiva.

A conformação do instrumento extrajudicial à rigorosos requisitos aptos a atribuir-lhes a natureza de título é, pois, imprescindível, como observa Carnelutti (1999, p.315), dado que enquanto o processo cognitivo se consubstancia na pretensão de submeter o interesse alheio ao próprio, sem que haja necessária identidade entre a pretensão veiculada pela demanda e o que prescrito pelo ordenamento jurídico, a execução reclama uma pretensão já reconhecidamente conforme o Direito.

Ao par desta discussão, verdade é que, seja na execução de obrigações reconhecidas judicial ou extrajudicialmente, certa é a necessidade da detenção pelo credor de um título, que se conforma a ideia de um gatilho à possibilitar que o Estado deite a mão sobre o domínio patrimonial do indivíduo, atuando a sanção normativa e 'modificando os atos da realidade para realizar a coincidencia entre as regras e os fatos' (THEODORO JUNIOR, 1999, p.45).

Essa existência do título como condição sine qua non para o exercício perante o Estado da pretensão de atuação prática da norma jurídica acabou por despertar na doutrina o desejo de definir qual seria sua natureza jurídica, discussão que acabou por se tornar uma das mais célebres polêmicas do direito processual civil moderno, como polos extremados por eméritos processualistas: de um lado Francesco Carnelutti e, de outro, Enrico Tullio Liebman.

\section{A TEORIA DE FRANCESCO CARNELUTTI: O TÍTULO EXECUTIVO COMO DOCUMENTO}

De fato, é mais a simplicidade aliada a logicidade do que a acuidade científica que seduz alguns intérpretes do Direito a se aliar a teoria da natureza jurídica documental do título executivo aperfeiçoada ${ }^{5}$ por Carnelutti.

$\mathrm{O}$ eminente processualista udinense constrói sua teoria sob o singelo exemplo do passageiro na estação de trem, in verbis:

O objeto que tem a função recém-delineada é um documento que o credor, com o fim de obter a execução forçada, deve apresentar ao ofício judicial, assim como o viajante deve apresentar o bilhete ao pessoal ferroviário; que o título executivo seja, portanto, um documento e não um ato, como por

\footnotetext{
${ }^{5}$ Assis (2002, p.143) salienta que Carnelutti não cria, tão somente recepciona a concepção de título como documento já encontrada em processualistas como Mortara, Ricci e Manfredini.
} 
muito tempo se acreditou, está esclarecido por essa simples comparação (CARNELUTTI, 1999, p.317).

Assim, tal qual a apresentação do bilhete propiciaria ao agente da plataforma certeza acerca do pagamento da passagem pelo viajante, dandolhe direito à viagem, para Carnelutti, o título permitiria ao magistrado a construção de um juízo de certeza acerca da existência de uma obrigação, possibilitandose ao jurisdicionado o acesso direto à retilínea via executiva, sem que se afigurasse necessário antes percorrer o sinuoso caminho do processo cognitivo.

Teria, portanto, o título executivo, função de prova, mas não qualquer prova, seria espécie de prova legal - aquela à qual dá o legislador força suficiente para possibilitar ao julgador reputar existente determinado fato sem que, contudo, haja necessidade de perquirir acerca da real existência dele.

Anota Zavascky $(1999$, p.57) que após as críticas de Liebman à sua teoria, Carnelutti reviu alguns conceitos, mas não deixou de defender a natureza jurídica documental do título executivo, limitando-se a reconhecer que a expressão prova legal antes empregada era, de fato, insuficiente à definição do fenômeno que objetivava circunscrever.

Expôs, então, Carnelutti em sua obra Derecho y Processo, que o título seria mais que uma prova legal; representaria aquele documento não só a existência de uma obrigação, como também implicaria no reconhecimento de que aquela obrigação era detentora de uma eficácia mais intensa, uma eficácia transcendente daquela que uma mera prova lograria ensejar (apud ZAVASCKI, 1999, p.58).

Embora de repercussão retumbante no universo jurídico, essa teoria que via no título executivo a mera documentação de um ato foi severamente objurgada por Liebman, no que foi seguido depois por diversos outros juristas.

\section{A TEORIA DE ENRICO TULLIO LIEBMAN: O TÍTULO EXECUTIVO COMO ATO JURÍDICO}

Por ao menos duas oportunidades ${ }^{6}$ Liebman criticou Carnelutti no que tange à teoria da natureza jurídica do título executivo.

Para o Mestre que tanto influenciou a escola processualista pátria, o título executivo tem natureza de ato jurídico, não de documento, sendo que a

\footnotetext{
${ }^{6}$ São obras em que Liebman se dedica ao tema: Manual de Direito Processual Civil e Embargos do Executado.
} 
própria parábola de Carnelutti para fundamentar sua teoria documental já conteria em si mesmo o germe da antítese.

É que para Liebman (1968, p.112) se o bilhete que possibilitaria ao viajante ingresso ao trem serve como prova do pagamento da passagem, provando o viajante ao bilheteiro, de qualquer outra forma, que a viagem fora paga, o embarque lhe seria deferido. De forma análoga, ainda que de posse do bilhete, fosse provada a ilegitimidade de sua aquisição pelo viajante, obstar-se-ia the o embarque.

A doutrina da natureza documental do título, nesse viés, teria o incômodo problema de lidar com a figura de uma execução dependente de prova (o embarque no trem condicionado à mostra do pagamento), ou pior, explicar a existência de uma ação executiva previamente à conformação do título (retirada do viajante do trem pela descoberta da obtenção do bilhete por modo ilegítimo), circunstâncias contraditórias ao escopo do título executivo.

O horizonte desenhado por Carnelutti, na ótica de Liebman, seria justamente o oposto daquele vislumbrado pela sociedade quando elaborada a teoria do título executivo, urgindo se advertir acerca do risco de confusão entre fonte da prova com o fato a provar, tal qual o de se atribuir ao documento a eficácia correspondente ao ato.

Ao receber o título e dar início aos provimentos executivo, ao Juiz não interessaria a efetiva existência do crédito (objeto de prova). O título, só por si, enseja a via executiva (eficácia do ato):

Título executório é, em conclusão, um ato jurídico dotado de eficácia constitutiva, porque é fonte imediata e autônoma da ação executória, a qual, por conseguinte, é, em sua existência e em seu exercício, independente do crédito [...] É assim que não somente se torna dispensável, mas supérflua e irrelevante qualquer prova do crédito: o título basta para a existência da ação executória(LIEBMAN, 1968, p.135).

Zavascki (1999, p.61) entende que o título executivo é mais de que um ato jurídico, sendo seu conteúdo verdadeira norma individualizada. Para o ministro do Superior Tribunal de Justiça, entender o título como mero ato, onde se acerta a sanção comprometeria o monopólio estatal do domínio da perinorma.

Esta posição é rejeitada por Dinamarco $(2009$, p.496) que explica que a crítica é infundada já que, se por um lado Liebman cometeu a imprecisão terminológica de referir-se invariavelmente ao título com ato jurídico, por outro, 
foi suficientemente explícito em esclarecer que é a lei e não a vontade particular, que liga a sanção a certos atos celebrados entre particulares.

Expõe também Theodoro Junior (1999, p.53) que para Liebman, portanto, o título executivo incorporaria a sanção; exprimiria a vontade do Estado de se proceder à determinada Execução, tendo verdadeira força constitutiva - $O$ título faz nascer a ação executiva.

A teoria do título executivo como ato documento encontra ainda críticas em solo pátrio nas obras de renomados juristas, dentre eles Cândido Rangel Dinamarco, Humberto Theodoro Júnior e José Alberto dos Reis.

Theodoro Júnior (1999, p.53), a seu turno, assevera que a superioridade da doutrina de Liebman sobre a de Carnelutti se estabelece em virtude da teoria documental deslocar a fonte da ação executiva para o 'ato de vontade do devedor', situando-a no âmbito do direito material, o que vai flagrantemente contra a acepção autônoma do direito de ação.

Estar-se-ia, em última análise, a seguir a lógica do título como documento, como mera retratação do ato, permitindo que o ato jurídico desse ensejo à ação executiva. Contudo, bastaria ter em mente que um mesmo negócio jurídico, mútuo, por exemplo, pode ou não dar ensejo a uma ação executiva, a depender da forma como este é firmado, e se logra demonstrar a falha do pressuposto teórico documental.

Dessa celeuma - título executivo ora como documento ora como ato abriu-se oportunidade do surgimento de outras teorias intermediárias, ditas ecléticas, que perscrutam encontrar, na conjunção dos postulados de Liebman e Carnelutti, a verdadeira natureza jurídica do instituto processual.

\section{TÍTULO EXECUTIVO COMO ACERTAMENTO DO DIREITO SUBJETIVO MATERIAL OU COMO ATO-DOCUMENTO}

Teoria extremamente complexa que tenta explicar por uma terceira via a natureza jurídica do título executivo é atribuída ao italiano Crisanto Mandrioli ${ }^{7}$. Este autor identifica a natureza jurídica do título como sendo a de prova da eficácia executiva de um ato de acertamento do direito.

Como explica Dinamarco (2009, p.486) não seria o título executivo, por esta teoria, gerador da ação executiva, mas uma condição para o seu exercício; 'o acertamento do direito é que faz aparecer a ação executiva pela

${ }_{7}$ Conforme doutrinam Greco (2001, p.113) e Dinamarco (2009, p.487). 
transformação da ação pré-existente'. Haveria pelo título executivo, segundo Mandrioli (apud GRECO, 2001, p.113) a prova do acertamento do direito substancial como existente e suscetível de execução forçada.

Critica-se esta teoria pelo fato de que, seguindo-se seus pressupostos, dar-se-ia eficácia executiva a sentença meramente declaratória, capacidade que embora suscite na doutrina acalentados debates, ainda é tida majoritariamente como afronta ao direito positivo.

A maioria dos estudiosos do processo civil ${ }^{8}$, por fim, acaba por adotar uma teoria mista acerca da natureza jurídica do título executivo, o definindo como ato-documento, isto porque, como bem preleciona Theodoro Junior (1999, p.54), acaba não sendo o ato jurídico material que enseja a oportunidade da execução, mas a sua incorporação formal em um documento com as feições específicas determinadas pelo direito processual.

Seria o título, de fato, um documento, mas documento revestido de formalidades legais que lhe torna apto a possibilitar seu portador utilizar da via executiva para satisfação do crédito por ele representado. Marques (2003, p.18) esclarece que a discussão que ora tentou imputar ao título tão somente a natureza de documento ora de mero ato é inócua, porque ele se reveste das duas características ao mesmo tempo, haja vista que sua força executiva provém da tipicidade ou enquadramento da prestação no tipo legal.

Como ato o título implica a vontade do Estado de possibilitar aos particulares a atuação da sanção em normas particulares. Como documento o título é imprescindível à execução, posto assegurar ao juiz a prescindibilidade de investigação acerca da existência do crédito. Mas há de se reconhecer que não se gera uma presunção absoluta:

Oportunizando a lei, através dos embargos, a destruição do título executivo - quando o direito não exista -, acaba condicionando o ato final executivo (que é propriamente a execução) à existência efetiva do direito substancial; $\mathrm{e}$ confirmando o entendimento de que o título executivo permite apenas que o credor inicie e desenvolva a atividade executória (que é a ação processual executiva), mas não possa atingir o resultado executivo, se o executado lograr demonstrar nos embargos, a inexistência do crédito, configurado no título (SILVA, 1997, p.33).

\footnotetext{
${ }^{8}$ Exceção à Dinamarco (2009, p. 498) que adota praticamente na íntegra a construção de Liebman, acrescendo tão somente que o título tem natureza não só de ato como também de fato.
} 
Mister destacar, por oportuno, as teorias desenvolvidas por Medina (2002) e Bueno (2008) quanto a natureza do título executivo. O primeiro entende que a distinção entre ato e documento pouco relevância representa para o direito processual, eis para o julgador ambas as características são relevantes para o deferimento da execução; ao depois, a importância do documento reside não na característica do título, mas na forma do ato ao qual a norma atribui eficácia executiva. Para o processualista marigaense, melhor seria para caracterizar a natureza do título regredir na especificação do fenômeno:

A única concepção capaz de demonstrar satisfatoriamente o fenômeno é aquela que vê, no título executivo, apenas e tão somente o suporte fático reconhecido pela norma jurídica como condição de atuação da sanção executiva no processo de execução, independentemente da averiguação da existência do direito que contém. (BUENO, 2008, p.119-120).

Para Bueno (2008) a natureza jurídica do título executivo deve ser entendida como probatória, isto porque exerce ele a função de elemento ensejante de convicção do magistrado, necessário à autorização do início do exercício dos atos materiais de realização do direito.

Releve-se que não desempenharia o título executivo papel de convencimento de existência de direito ao magistrado, mas, tão somente, existência de suficientes elementos à possibilitar ao seu detentor acesso à via executiva:

É que o título executivo dispensa que o magistrado se indague sobre a existência do direito. Até 'segunda ordem' o direito que tem de ser satisfeito é aquele suficientemente documentado no (e pelo) título. A hipótese, por isto mesmo, é de presunção; presunção no que assume prova em contrário presunção juris tantum, portanto - mas presunção, e como toda presunção, apta a dispensar a produção de quaisquer provas daquilo que ela, a presução, prova suficientemente (BUENO, 2008, p.75).

É a linha de raciocínio similar a de Marinoni e Arenhart (2008, p.429) que reconhecem que, por vezes, um dos aspectos, [documento ou ato] prevalecem, mas os dois se somam para formar a realidade do título - a de condição bastante para que o exequente inicie a execução. 


\section{CONCLUSÃO}

A verdadeira cizânia entre Liebman e Carnelutti não se está na definição da natureza jurídica do título executivo, mas sim nas concepções que aqueles processualistas tinham de processo executivo.

Enquanto para Carnelutti o título geraria no magistrado a presunção da existência de um direito material, apto a dispensar a atividade cognitiva e a ensejar a pronta atuação da norma jurídica, Liebman enxergava no próprio título a fonte do direito a execução, desprendendo completamente a existência do direito material do direito à tutela processual.

Ocorre que, neste sentido, é preciso dar razão à Carnelutti: hodiernamente se afigura impraticável uma prestação jurisdicional desprovida de qualquer raciocínio cognitivo a perquirir sobre o direito material que funcional como pano de fundo da lide.

O mito da execução sem cognição parece ficar cada vez mais no passado, garantindo-se cada vez mais ao magistrado a possibilidade de examinar a relação jurídica que fez surgir o crédito que se busca satisfação. $\mathrm{O}$ título é abstrato, mas não tão abstrato. $\mathrm{O}$ abstratismo radical levaria à autorização de uma execução, ainda que a inexistência do crédito já fosse dada como certa, prestação jurisdicional que desbordaria completamente do conceito de acesso à Justiça que tenta se dar à garantia constitucional.

O processo não pode mais ser visto como mera sucessão de atos. Cuida-se de instrumento de efetiva realização dos direitos subjetivos quando violados ou ameaçados. E deve ser de realização pronta, célere e pouco onerosa. Enfim, um processo a serviço de metas não apenas legais, mas, também, sociais e políticas, seguindo os seus escopos naturais. Um processo que além de ser legal, seja sobretudo um instrumento de distribuição de justiça.

Enfim, a doutrina jurídica ao se debruçar sobre a questão da natureza jurídica do título executivo pode até não chegar a uma conclusão definitiva - se afinal se trata de ato, documento ou ato-documento o conteúdo daquele pedaço de papel que o credor apresenta ao juiz - mas uma certeza inexorável se extrai de toda a celeuma: o reconhecimento da eficiência do processo executivo para que se atinja o escopo maior do processo - a efetividade. 


\section{REFERÊNCIAS}

ASSIS, Araken de. Manual de processo de execução. 8.ed. São Paulo: Revista dos Tribunais, 2002.

BUENO, Cassio Scarpinela. Curso Sistematizado de Direito Processual Civil: tutela jurisdicional executiva, 3. Ed. São Paulo: Saraiva, 2008.

CARNELUTTI, Francesco. Instituições do Processo Civil. Campinas: Ed. Servanda, 1999. v.1.

DINAMARCO, Cândido Rangel. Execução Civil. 8.ed. São Paulo: Malheiros, 2002.

GIACÓIA, Gilberto. Justiça e dignidade. Em Tempo, Marília, v.6, p.27-37, ago. 2004.

GOMES, Sergio Alves. Hermenêutica constitucional: um contributo ao Estado Democrático de Direito. Curitiba: Juruá, 2008.

GRECO, Leonardo. O processo de Execução. Rio de Janeiro: Renovar, 2001. v.2.

. O processo de Execução. Rio de Janeiro: Renovar, 1999. v.1.

LIEBMAN, Enrico Tullio. Embargos do Executado: oposições de mérito no processo de execução. 2. Ed. São Paulo: Saraiva, 1968.

. Manual de Direito Processual Civil. Tocantins: Ed. Intelectos, 2003. v.1.

MARINONI, Luiz Guilherme; ARENHART, Sérgio Cruz. Curso de Processo Civil. Execução. 2.ed. São Paulo: Revista dos Tribunais, 2008. v.3.

MARQUES, José Frederico. Manual de Direito Processual Civil. 9. ed. Campinas: Millennium, 2003. 
MEDINA, José Miguel. Execução Civil: princípios fundamentais. São Paulo: Revista dos Tribunais, 2002. (Coleção Estudos de Direito de Processo Enrico Tullio Liebman).

SILVA, Ovídio Araújo Baptista da. Jurisdição e Execução na tradição romano-canônica. 2. ed. São Paulo: Revista dos Tribunais, 1997.

. Curso de Processo Civil. 4. ed. Rio de janeiro: Ed. Forense, 2007.

THEODORO JÚNIOR, Humberto. Curso de Direito Processual Civil: teoria geral do Processo Civil e processo de conhecimento. Rio de Janeiro: Ed. Forense, 2007.

. Processo de Execução. 19. ed. São Paulo: Ed. Leud, 1999.

ZAVASCKI, Teori Albino. Título Executivo e Liquidação. São Paulo: Revista dos Tribunais, 1999. (Coleção Estudos de processo Enrico Tullio Liebman).

Recebido em: 2012-05-13 Aprovado para publicação em: 2013-08-16

Como citar: PIOTTO, Danillo Chimera; BALEOTTI, Francisco Emílio. Anatureza jurídica do título executivo: da polêmica instalada entre Liebman e Carnelutti às teorias que se seguiram. Direito Público, Londrina, v.8, n.2, p.159-172, mai/ago.2013. DOI: 10.5433/ 1980-511X.2013v8n2p159. 